\title{
Practices of Body Management: Transgenderism and Embodiment
}

\author{
MARK FINN and PIPPA DELL* \\ Department of Psychology, University of East London, Romford Road, London E15 4LZ, UK
}

\begin{abstract}
(Dis)ordered body management practices such as transgenderism and anorexia are largely conceptualized within psychology as the pathological manifestation of individual distress. It is argued that the way they are talked about, treated and ultimately understood as matters of and for health, serves the regulatory (socio-cultural and political) function of targeting more visible embodiments as problematic and indicative of distressed subjectivity. A poststructuralist discourse analytic is employed as a means of exploring alternative constructions and understandings of problematic embodiment. It is proposed that transgenderism discursively and materially relocates (dis)ordered embodiment from the constituting realm of health to that of productive choice, wherein the notion of distress is questioned. As a matter of choice, gender (re)embodiment is understood as potentially positive, pleasurable and a site for non-distressed multiple subjectivities. From this, it is suggested that community, health and social psychologists re-evaluate current constructions of 'problematic' body management practices, account for their wider social and political function, and attend to ways in which non-distressed management can otherwise be understood and supported. Copyright (C) 1999 John Wiley \& Sons, Ltd.
\end{abstract}

Key words: transgenderism; body management; embodiment; transsexuality; discourse; public health; subjectivity

\section{INTRODUCTION}

In the late twentieth century, characterized by advanced consumer capitalism, the body has become the ultimate commodity to be managed (Featherstone, 1991), whether through, for example, regulation of food intake, exercise, or by submitting it to the surgeon's knife. As a result, over the last few decades a complex relationship has developed between psychology, psychiatry, medicine and those body management practices that are deemed problematic and potentially dangerous. In this paper, we

* Correspondence to: Dr. Pippa Dell, Department of Psychology, University of East London, Romford Road, London E15 4LZ, UK.

CCC 1052-9284/99/060463-14\$17.50

Copyright (C) 1999 John Wiley \& Sons, Ltd. 
want to explore some of the complexities of (dis)ordered ${ }^{1}$ embodiment, that is, seemingly unnatural and negative types of body management, by drawing on the experiences and conversations of a selection of individuals who self-identify as 'transgender'. ${ }^{2}$ Recent theorizing on transgenderism tends to bypass what transgender individuals themselves say and think about their own lives (Kulick, 1998). These gender transgressors are often consciously engaged with re-producing their (sexed and gendered) bodies through a variety of body management practices such as clothing, hormones and surgery. However, whilst acknowledging to varying degrees an uneasy relationship with their culturally defined bodies, transgenderists also actively (dis)engage with those normalizing psychiatric and medical discourses (c.f. Foucault, 1979; Rose, 1989) that construct and produce the gender dysphoric body (that is, nonalignment of sex and gender) as a 'pathological' one (Parlee, 1998; Whittle, 1996; Bornstein, 1994). Their re-constructive and political activism, we would argue, offers critical insight into current psychological understandings and treatments of individualized distress to do with embodiment and subjectivity, as well as simultaneously exposing ways in which the (private) body is regulated and shaped by wider (public) health discourses.

Drawing on the work of Douglas $(1966,1982)$ who denotes the body as a system of 'natural symbols' that reproduce the complexities of our social world, and that of Crawford (1985) who argues that the economic structure of this social world is contradictory, relying as it does on production and consumption, Bordo (1990) has distinguished between 'producer-selves' and 'consumer-selves'. As producers 'we must be capable of sublimating, delaying and repressing desires for immediate gratification' in our cultivation of the work ethic, whilst as consumers 'we serve the system through a boundless capacity to capitulate to desire and indulge in impulse' (Bordo, 1990, p. 96). Despite the suggestion that 'discipline and hedonism' as body maintenance routines are no longer incompatible (Featherstone, 1991, p. 171), this oppositional relationship can nevertheless be seen to impact on our bodies in that how they can be (and indeed are) construed and understood is vastly culturally and discursively bound ${ }^{3}$ (Malson, 1998). For example, as producers of commodities our bodies have the potential to become our finest productions, healthy and aesthetically pleasing (Bourdieu, 1984) and regulated by a 'well-ordered self' (Bordo, 1990, p. 96). This particular construction of the body allows (dis)ordered embodiment, such as anorexia for example, to be understood as spiritually purifying (Bordo, 1990) and aesthetically pleasing. As an example of the notion of productivity working as a discursive framework and forming a particular understanding of such practices, Medieval understanding of selfstarvation as an ascetic religious act (firmly located within a Catholic discourse), understood regulation of food intake as a productive 'method of spirituality' rather than as 'individual pathology' (Malson, 1998, p. 50).

\footnotetext{
${ }^{1}$ This bracketing off of the prefix 'dis' in the word 'disordered' signifies throughout this discussion its underlying questioning of the current separation of non-distressed (ordered) body management practices and distressed (disordered) ones.

2 'Transgenderism' refers to all currently identified cross-gender expressions that do not fit the diagnostic criteria of transsexuality and transvestism. As such, the term transgenderism is the currently favoured (but not universally accepted) one. Other terms include transpeople; gender-blenders; gender outlaws; crossdressers; drag kings and queens.

${ }^{3}$ To say that the way in which bodies are understood is 'discursively bound' is to suggest that they are made sense of and known through talk, texts and writing that produce particular understandings of the 'reality' of bodies. 
As consumers of commodities, however, our 'desiring' bodies tend to be interpreted as excessive and unrestrained, seemingly out of our control, potentially pathological, and thus an origin of psychological distress. In this discursive context, that is, by talking about bodies in this way, body management strategies like transsexuality, anorexia and elective cosmetic surgery are deemed as often extreme and dangerously self-destructive. The point being made is that various body management practices can be seen to stem from pre-existing historical, socio-cultural and political discourses that regulate ways in which particular practices are systematically understood, allowed and valued (c.f. Bourdieu, 1984). Anorexia is, of course, not being underplayed as merely discursively dangerous; the physical ramifications can indeed be life threatening unlike a cosmetic nose job, for example.

The linkage between the seemingly disparate non-homogenous categories of transsexuality, anorexia and elective cosmetic surgery is that inherent within understandings of these examples of different kinds of body management there is at work a contradictory paradox in that theory and narratives surrounding the three categories include notions and talk of both self-production and self-destruction. It is suggested that this paradox can be seen to hinge (among other things) on the economically and culturally crafted productive/consumptive distinction. While these three expressions of body management are often regarded as damaging forms of self-mutilation (e.g. Lienert, 1998), the more positive idea of non-distressed self-production has also been referred to in analyses of anorexia (Malson, 1998), cosmetic surgery (Davies, 1995) and transsexualism (Riddell, 1996). For example, in focusing on the related but conflicting themes of self-production and self-destruction surrounding understandings and experiences of anorexia, Malson (1998, p. 187) highlights 'a multiplicity of positive as well as negative subjectivities ...' Similarly, Davies (1997, p. 24) argues for viewing cosmetic surgery as 'a complex dilemma: problem and solution, symptom of oppression and an act of empowerment, all in one'.

The productive/consumptive opposition also helps to clarify the postmodern distinction made between the 'transsexual' (as consumers) and the 'transgenderist' (as producers) in that critics of transsexual therapy have aligned it with late capitalist consumer culture where 'sexual fulfilment and gender-role comfort are portrayed as commodities, available through medicine ... [pushing] patients towards an alluring world of artificial vaginas and penises rather than towards self-understanding and sexual politics' (Billings and Urban, 1996, p. 112). It is against the rejection of and separation from the 'consumerist' construction of transsexuality, and the consequent pathology ascribed, that the postmodern transgender identity is able to be reinterpreted as a non-distressed, non-pathologized one, as the product of sexual and gendered activism.

We emphasize that it is not our intention to perch transgenderism on higher moral ground for not always buying into medico-psychological discourses and practices, thereby privileging it as a postmodern, subversive and queer identity. Like Prosser $(1998$, p. 7$)$, transsexuality is here not denounced as merely 'a kind of unwitting technological product'. Indeed the distinction between transgenderism and transsexuality is not an easy one to make as some feminists and others (e.g. Lancaster, 1998) point out. Sheila Jeffreys, for example, argues that the so-called new transgenderists of the nineties armed themselves with poststructuralist theory that challenged the idea of biologically fixed gender in order to '... take the high political ground and criticize feminists for their political conservatism' (1997, p. 57). Feminists 
like Jeffreys (1997) and Leinert (1998) are highly critical of gender transgressors of whatever nature (particularly male to female) on the grounds that such selfmutilation or pretence is a violation of female and therefore of human rights. According to a radical feminist political agenda, the criticism is a valid one but in its reference to concepts such as 'self-mutilation', 'physical integrity' and 'native bodies' that should not be interfered with (see Jeffreys, 1997), an underlying unhealthy dysfunction at the heart of gender transgression is assumed that in turn provides feminism with its own moral high ground.

Our purpose in highlighting a distinction between transsexualism and transgenderism is so that a more positive understanding of gender transgression as a form of body management can be encouraged. While transgenderists playing with gender to whatever extent can be seen to reinforce gender hegemony as much as postoperative transsexuals are often said to be doing (e.g. Raymond, 1994), those who self-identify as transgender are here distinguished because of their particular potential in challenging the myth of individual distress which is currently believed to necessitate less normative body management practices.

The focus of this paper, therefore, is to explore the complexity of bodies, their meanings and their management in terms of the social, cultural and political contexts that can be seen to produce and dichotomize notions of distress and non-distress. In particular it will be argued that, unlike other managed bodies such as the obese body, the cosmetically reconstructed body and the transsexual body, which have been understood predominately as consumptive and thus defined in terms of psychological distress (Cooper, 1998; Lienert, 1998), the transgendered body can be seen as productive and a site for the re-negotiation of such (negatively) embodied and distressed subjectivity. As Parlee (1998) points out, those who do not identify with the limited medical classifications of transvestism and transsexuality (or accept associated diagnostic criteria) are not comprehended by scientific and psychological theory. Consequently, current health practices are not seen to include the support of transgenderists who are physically and/or psychologically managing their bodies as both genders or who alternate between them over a period of time.

Bordo refers to a preoccupation with the alien and uncontrollable (consumptive) body as one which functions as a powerful 'normalizing' strategy that ensures 'the production of self-monitoring and self-disciplining "docile bodies", sensitive to any departure from social norms, and habituated to self-improvement and transformation in the service of those norms' (Bordo, 1990, p. 85; c.f. Foucault, 1977; Butler, 1990). Given that taking up a position outside the conventional gender norm is largely problematic, it was necessary for the bodies of those with cross sex and gender desires to be understood as commodities and thus made docile so that such transgression could be attended to, policed and ultimately resolved (Foucault, 1979). Such bodies were construed as docile in that they were (and are) constructed as the product of a (consumptive) pathological individual; the basis of gender dysphoric pathologies being that gender expression and biological sex are not congruent.

In this way, medical and psychological concern with difference from the gender norm (itself predicated on wider social and cultural fundamentalisms), is deterministic in its assumption that such individuals are pitiful 'victims' of whatever biological or environmental function, rather than capable of making valid choices that may not be about full appropriation (or consumption) of the opposite sex and gender. Dallas Denny addresses this issue by arguing against the notion of the 'true' 
transsexual. She asks should medical technology '... continue to be available only in an all or none fashion, with the inevitable goal being to produce picture-perfect males with neophalluses and females with neovaginas? Or should it be available, as are other body medical technologies, in piecemeal fashion to those who can give informed consent?' (1996, p. 41). For the transgender person, whilst the body may be subjected to scrutiny, and for some deemed alien, it is exactly its (embodied) departure from social norms that becomes the impetus for political action and the renegotiation of subjectivity: our sense of self, who and what we are. Moreover, for those who do engage in this type of body management there is a preference for fluidity, a body under (de)construction, rather than a body permanently fixed or sexed (c.f. Parlee, 1998; Whittle, 1996; Bornstein, 1994). Distress, if it occurs, emerges in and through the struggle to free the body from socio-cultural imperatives and 'normalizing' psycho-medical discourses and practices that restrict choice, pleasure and (body) freedom. Similarly, among anorexics, medical intervention has been criticized as being iatrogenic, that is, an unnecessary invasion and distressing in itself (Newton et al., 1993). Indeed, the 'body-as-fluid' (whether materially or psychologically performed) has been found to provide its inhabitants with considerable pleasure and comfort in not being construed as a problem that warrants prescribed intervention (Bornstein, 1994).

The aims of this paper are to present and explore body management practices that are centred around the re-construction of sex and gender but which do not rely on the dictates of public health policy/practice and the inherent (socially constructed) assumption that a coherency between gender and physical sex is indicative of health. By focusing on 'the diverse and self-aware transgendered community's reflections on its own personal/political praxis in relation to dominant social institutions and ideologies' (Parlee, 1998, abstract p. 120), it is hoped that their knowledge and experience can be used to challenge ways in which body management practices are discursively constructed within academic and public health arenas. The argument presented is that the emphasis on psychological distress around (dis)ordered embodiment serves to warrant particular body management practices (such as the intervention of sex re-alignment surgery) that are regulatory in purpose and function and which are constituted by wider socio-cultural imperatives.

\section{METHODOLOGY}

\section{Participants}

Seven participants were recruited from a pool of social contacts available to the authors and were specifically targeted because they self-defined as transgendered and employed a range of body management practices including the use or non-use of sex hormones and reconstructive surgery (not genital). All have cross-dressed (either permanently or intermittently) and two have returned to their prior gender since receiving hormone treatment. The sample comprises three 'biological' men and four 'biological' women with ages ranging from mid-twenties to mid-forties. ${ }^{4}$ Gender

\footnotetext{
${ }^{4}$ David (transgendered female to male, White British) is currently using male sex hormones; Marcus (transgendered female to male, White American) has had a bilateral mastectomy and has used male sex hormones, but has now suspended treatment because of health concerns and wishes to conceive; Chris (drag king, female to male, White British) cross-dresses sometimes as a man and identifies as such but has 
pronouns used in this analysis correspond to those used by the participants themselves and to the gender identities each have adopted.

\section{Discourse analysis and procedure}

Unusually this study is based on both transcripts ${ }^{5}$ of interviews carried out in a faceto-face situation in the participant's own homes, and on text from interactive e-mail sessions with one participant (Marcus) residing in the US. This variation in procedure should not be seen to compromise the discourse analysis employed in this study as it is not one which relies on defining discourse as merely the spoken word, but is concerned with both written and spoken language as text (c.f. Potter and Wetherell, 1987). Moreover, this language is not seen as reflective of some underlying psychological reality, but rather as productive of that reality (Foucault, 1972; Hall, 1982; Burman and Parker, 1993). It is therefore the participants' language itself that becomes the object of analysis.

Discourse analysis is employed as a methodology of particular relevance to this subject area in that it accounts for psychological phenomena as 'public and collective realities' (Burman and Parker, 1993, p.1) and allows for investigation of the surrounding social and cultural imperatives that help to produce the subject under analysis. In other words, this more critical methodology recognizes selves and psychological properties as produced through culturally available and mutually recognizable talk, narratives and systems of meaning rather than treating psychological processes as separate to them. Of particular concern was an explication of those discourses which constitute and regulate the transgender experience of body management; allowing transgenderism to be explored and understood through its own words and on its own terms. The analysis also incorporates poststructuralist feminist concern with how discourse analysis engages with the extra-discursive of social reality and of corpo-real bodies (e.g. Ussher, 1997; Malson, 1997); that discourses have powerful physical effects on (discursively) embedded and embodied subjects.

A structured format of questions was not used in favour of conducting naturalistic conversations with participants (c.f. Malson and Ussher, 1997). This is not meant to imply that the conversations held were any more 'real' than a structured interview, but it does mean that the researchers were not advantaged (nor conversation constrained) by presentation of a list of questions that pre-supposed areas of significance. It was integral that participants themselves guide areas of importance as it was assumed that transgender experiences and commentaries are non-homogenous and likely to vary.

not taken testosterone; Penny (transsexual male to female, White British) having taken female sex hormones and lived as a women for 5 years, now lives as a man but still identifies as transsexual; Steven (transgendered male to female, White British) frequently cross-dresses as a women; Michael (drag performer male to female, Black American) performs as a drag artist. Rosa (transgender female to male, White European) received testosterone and lived as a man for 3 years, has now stopped hormones and identifies as a woman. Despite these categorizations it should be noted that participants were reluctant to classify themselves in terms of already existing sexes and genders.

${ }^{5}$ The transcription code used in this analysis indicates speech features such as pauses and emphasis but it is the readability of the text which is stressed. In the transcripts italics indicate emphasis of words; (.) indicates a pause greater than 4 seconds; $=$ refers to an absence of a pause between two utterances; ... indicates part of the transcript has been omitted; [ ] are used to distinguish participants' speech from points of clarification used by the interviewer. All names and identifying references have been changed, with the exception of Penny who did not wish to be anonymous. 


\begin{abstract}
ANALYSIS AND DISCUSSION
In order to expound the concerns of this paper and to address its aims, the analysis is structured around three emergent themes: the pathological body as unhealthily 'visible'; the relocation of gender re-embodiment and management from the discursive realm of health and distress to that of 'choice'; and the productivity of choice in terms of the non-distressed experiences and subjectivities of those who choose to manage their bodies as differently gendered.
\end{abstract}

\title{
The (in) visible body
}

Following poststructuralist theorizing that challenged received 'truth' of gender (e.g. Foucault, 1979; Butler, 1990), transgenderism, with its very different political agenda (Bolin, 1994), can be seen to overtly question existing categories that are seen to construct specific and limited understandings of both traditional sex/gender and gender dysphoria as typified by medico-scientific theory. While not all transgenderists are taken to be subversive in this way, transgenderism does have the potential to offer a critical take on what is taken for granted, on what is accepted as real (Butler, 1998). A common distinction emerging from the narratives/conversations is between structured rigidity on the one hand, and a fluidity that is about prioritizing individuality, difference and variation over categories of commonality on the other hand. Reference is typically made to the scientific and medical constructions of gender and gender dysphoria that establish certain truth claims and provide particular subject positions that compel appropriate activity extant in our culture, such as sex-role behaviour. For some transgenderists, transsexuality is an example of this process and thus construed as an irrelevant category/identity for those who prioritize fluidity or do not wish to completely appropriate the opposite sex and gender as part of their gender transgression/management.

Marcus: The medical establishment sets up two choices for gender, sex and gender presentation. If you are indeed transsexual (and only they really know for sure) then you must proceed from point A to point B as quickly and successfully as possible with no dallying in between, and certainly no wilful remaining in between. People who identify as both genders, or neither, or something completely different, have no role in the psychiatric model for transsexuals. According to them, transgendered people (I'm using that as people who identify as differently gendered but not necessarily transsexual) don't transition successfully.

Steven: Yer, I'm talking specifically about, you know, like someone in the past might be kind of diagnosed as being a transsexual and then they would be encouraged to have surgery say, but that might not necessarily be the best thing for them. It's just that they were diagnosed according to the medical model that that would be the best thing for them, for their mental health or whatever ... To align yourself with the gender stereotypes which are already there is to be seen as a healthy member of society. That's more a fault of the psychiatric profession I think, because it's suggested that someone can only be happy in a role if they go along with it whole-heartedly. It would be seen as being mentally unsatisfactory if someone had male to female surgery but then still maintained some of their male characteristics. That's seen as a bad thing and (.) Previously in the past there's been a lot of emphasis on conformity and becoming invisible in society, not being visible as a transsexual, but as being a 
women. For people to identify as being transgender is really to acknowledge their biological and sexual origins and not to become invisible in society ... I think transsexuals are quite keen to differentiate themselves from other transgender people by kind of like saying that they have a much harder time, that they're more tortured and that they suffer more from their transgenderness.

For Marcus and Steven, current emphasis on the transsexual identity is problematic because of its underlying (socially constructed) assumption that sex/gender coherence and conformity is representative of mental health. Such a health imperative is seen to have erroneously necessitated and privileged one way of 'successfully' transgressing the gender divide. Moreover, having identified this imperative, Steven talks about it as actively working to render gender non-conformity 'invisible'. Given that aligning oneself with 'gender roles and stereotypes' is seen as healthy, non-alignment consequently becomes indicative of an unhealthy body which, Steven suggests, is medically and socially constructed as a 'visible' one. Public health discourses can in this way be seen to be both constituted in and constructive of bodies that are understood, managed and treated as visible or invisible. In discursively exploring his understanding of transsexuality through the concept of (in)visibility, Steven exposes the regulatory workings of a health regime that is concerned with normalization and the productivity of inconspicuous, healthy bodies. Late capitalist consumerism, together with the influence of Cartesian (mind-body) dualism that diminishes the body, help provide the social and discursive framework in which this aspect of public health discourse and practice operates. In its construction of health and beauty ideals and imperatives, consumerism produces and prioritizes the indiscernible, 'docile' and 'useful' (Foucault, 1977) body. The result of this can be seen to give rise to a catalogue of body management strategies such as transsexuality, anorexia and elective cosmetic surgery that are about 'normalization' and invisibility. According to Davies (1995), women opting for cosmetic surgery do not necessarily want to be made beautiful but rather 'normal'. Such 'normality' is achieved via the consumption of popularized beauty ideals that produce a particular look, one that is essentially invisible in its typicality. Similarly, the anorexic in living up to the ideal of the thin, attractive woman (as one construction of the practice; Malson, 1998), may be psychologically in control while managing her body as a disappearing one; one that literally becomes invisible through its implication in wider health, consumerist and Cartesian discourses that construct female body invisibility as desirable, necessary and ultimately healthy.

\section{Not dressed with distress}

By locating gender dysphoria in the realm of health/non-health, the 'non-aligned' body, it is suggested, subsequently becomes visible and thus necessarily constructed and treated as dysphoric and pathological. It is because (sex and gender) body management is firmly situated within discourses around mental and physical health that people involved in such practices, to whatever extent, are understood to be doing so in order to fix or cure an internalized disorder. In this discursive context, visible sex and gender non-congruity becomes symptomatic of 'illness' (transsexuality) that produces sufferance and the need for surgery; a sufferance that in turn can be seen to validate the transsexual identity.

Steven: There's lots of, I'm generalising, but some transsexuals are keen to emphasise how special they are and how different they are to everyone else and would try 
to convince me that I was not a transsexual and completely different to them and it's quite difficult to argue that with someone who is standing in front of you who's had major surgery and everything else.

Because sex and gender coherency are institutionally and culturally constructed as indicative of a healthy mental state (Wilson, 1997), surgery which achieves this can only be good. Furthermore, that transsexuals surgically adapt their bodies can be seen to serve as the validation for this identity. The suffering that is used to establish what Steven sees as a hierarchy of gender transgression gains its power from the historical Judeo-Christian construction and practice of sufferance as righteous, to be rewarded and respected. While this is not to undermine the suffering that transsexuals may experience, this notion of sufferance can be seen to serve a clear function of validation. The consequence of discursively constructing gender transgression as a matter of and for health is that associated body management and individual distress remain tightly inter-linked. By acknowledging health as only one discursive framework in which body management is practised and understood, other discursive contexts can be seen to emerge and the separation of 'problematic' body management from individual distress and anguish becomes theoretically, discursively and materially possible.

Two significant functions of the transgender narrative are: first, the separation of this type of body management from individualized distress; and second, the subsequent relocation of gender re-embodiment from the constituting framework of pathology and distress to that of choice.

Marcus: When the value I place on myself, and my identity differ from my presentation, I have a choice either to go along with peoples' perceptions or educate them about my choices, issues and identity.

Michael: I think humans have choice and expressions of gender. The way I view it [i.e. gender] is that (.) I see it like hair colour and (.) it's much less fixed than we're taught it ... Gender is about using all the shit we know, but is not defined by all the shit we know. There are still many ways to do different things and you do have to look at it like taking on and off your clothes or changing your hair colour.

David: ... you look at men and you look at women. Those are basically the two choices on the table. Most people don't see that there could be a choice, but I do. I don't suffer. I was going to say that I don't suffer as much, but I don't actually see that I suffer. I don't think that I suffer from gender dysphoria. I've given myself the challenge. It's all very pragmatic. This is how I can be happy. This is what works for me.

What is evident in these extracts is a significant move away from concepts of internalized gender incongruity and associated individualized pathology. Having disregarded the rigidity of gender dimorphism and the categories of gender dysphoria it propagates (transsexuality and transvestism), perceived choice becomes a fundamental and productive activity for transgender people; an activity that simultaneously confirms this rejection of dimorphism while creatively using wider possibilities of sex/ gender embodiment and subjectivity. In talking about gender as a range of possible expressions from which one can choose, like 'hair colour', the transgender discourse constructs gender as a matter of and for choice, implying that gender identity is an activity that is not stable and, therefore, unstable ('dysphoric') identity not a site for distress or pathology. What is articulated here is Butler's (1990) notion of gender as a 
constructive doing that one has a pro-active role in, rather than a way of being. As a highly visible and performative 'doing', transgenderism is seen to have emerged from a discourse centred on choice, defrocking itself from the constituting and privileged garb of pathology and sufferance. For those who have chosen to access the normalizing health regime in order to receive desired hormone treatment (and for some, surgery), it is the required diagnosis and costly treatment, the 'two choices', the pathological 'role' and other people's perceptions that are cited as the causes of distress hitherto ascribed to the presenting individual. Where medicine and psychology targets the visible body as symptomatic of illness, the transgender body in actively and politically removing itself from this discursive context, presents itself as symptomatic of choice. What then are the implications for those subjectivities that are defined and fashioned against the discourse of choice as opposed to those dressed up in distress?

\section{The productivity of choice}

In order to explore the enabling power and the material effects of choice, the focus of this analysis moves on to the productivity of choice in terms of its subjective ramifications and the production of non-distressed (managed) subjectivities that it makes possible. When talking about sex and gender, Michael emphasizes personal responsibility as enabling him (and others) to free himself from having to fight with existing gender classifications.

Michael: You totally like have to chip away at the bitches, spray paint them, stomp on them - kick 'em - throw them up against a wall-make 'em manageable, you know. In that you're taking on responsibility for the creation of them ... And if you don't take on responsibility for creating it then you're powerless against it and it becomes then an enemy that you fight against.

Here the construction of gender (re)embodiment as a matter of choice clearly allows Michael to not feel victimized or pathologized by his material and psychological expression of both genders. Distress is significantly attributed to the powerlessness inherent in not perceiving choice. Similarly, when asked about her experience in living again as a man and re-managing her body as such, Penny says:

Penny: I saw how I could use it as a choice. Although I feel like a woman in my mind, I don't want to shave for two or three days and I don't wanna put make-up on and I can still be Penny with that. I'd always felt like I was a woman and it didn't matter if I had a beard on my face, it didn't matter if I had short hair, the feelings inside were that I was a woman.

The internal/external split that Penny sets up is typical of transgender discourse around choice, significantly constructing (internal) gender identity as something that does not need to be inscribed upon (external) bodies which are then managed accordingly. Cartesian dualism, as a pre-existing discursive resource, is here used as a justification for (gender and physical) inconsistencies and choices and not as warranting a mind that must remain in control of and subvert a 'wrong' body as it appears to do for some transsexuals, some anorexics and other 'sufferers' of eating disorders (Malson, 1998). In this way, the choice discourse as utilized by transgenderists, while not being totally separate to surrounding discursive resources and dichotomies (mind-body, male-female, individual-societal), does function as a 
variation of them in such a way that the body is constructed as fluid and not emblematic of a static and stable subjectivity. Here subjectivity is generated through the learning and use of a host of discursive repertoires and practices rather than by an autonomous, pre-existing and coherent 'self'; bodies and subjectivities are understood as being multiply constituted in discourse (Davies and Harré, 1990).

Besides generating a sense of freedom, creativity and (material and subjective) fluidity, also apparent in the choice discourse is the pleasure and sense of being advantaged that further undermine notions of distress inherent in health discourses. Pleasure results from what the body can do as opposed to what capitalist consumerism and hetero-patriarchal hegemony dictates it should do.

Marcus: I think that many people socialised as women are not given the message that they are just as entitled to physical pleasure as their partners. I learned this before hormones to a degree, but the additional comfort with my naked body after hormones made it possible for me to be even more comfortable. The increased libido from hormones [testosterone] and the changes in my sexual response cycle made me feel even better about it all ... I know that getting pregnant and having a kid doesn't change who I am [a male]. It is a thing my body can do, and I'd like to try to do it ... People will see something incongruous - someone with a beard who looks pregnant and make up an explanation for themselves.

Penny: Although I do have a penis and do have breasts, I love my breasts and whatever they are going to do to my body later in life, they've given me immense pleasure ... I like the fact that I am both. I can enjoy the fact that I can go out as a woman and live a certain way and do certain things, and I like the idea of being a male and being that quieter side of me ... Being transgender in a way does open up a whole other world that ordinary people don't always get.

As indicated in these example extracts, the productivity of choice hinges around physical pleasure, enhanced (multiple) subjectivity, enjoyment and a flexibility is that experienced by a body that variously manifests the (physical and behavioural) attributes of both sexes at different times and to varying degrees. What is significantly absent from this sample of transgender narratives is reference to any internal psychological distress or sufferance precipitating choice or experienced because of choice. While this could be construed as a silent validation for their particular choices (e.g. not having surgery), it is suggested that within transgender discourses validation for this identity/subject position rather centres around the notion of an 'ambiguity' that is invested with pleasure, comfort and the freedom to continually change and adapt one's body. The point is that transgender body management, predicated as it is on the perception of choice, demonstrates that body management practices hitherto seen as relieving distress are also about experiencing the pleasures of 'what the body can do' and how the associated fluctuation of embodied subject positions makes pleasures, life experiences and identity less 'ordinary'. That Marcus's highly conspicuous, pregnant 'male' body would be regarded as something 'incongruous' is the result of the limitation of choice imposed on bodies by heteropatriarchal hegemony, wherein the inevitably sought after explanation for such visible incongruity is not legitimized but rather targeted as a personal health issue and seen as problematic. 


\section{CONCLUSION}

From this particular reading of examples of transgender narratives, transgenderism is presented as a site on which the issue of distress around 'problematic' embodiment can be understood as but one discursive framework or context in which such body management practices are currently understood and treated. It is the dominance and function of notions of distress and non-distress themselves that are here regarded as problematic. Hegemonic social, cultural and political discourses serve to locate 'gender dysphoric' and other forms of 'abnormal' body management practices such as anorexia, within the realm of physical and mental health. As a result of this discursive construction, sustained as it is by the workings of a capitalist agenda and Cartesian dualism, the 'normal' body (rendered invisible through consumption) is legitimized as healthy, while the (productive) visible body is regulated precisely because its visibility is construed as symptomatic of internal distress. This alignment of visible and (dis)ordered embodiment with personal distress is the point at which medical and psychological intervention is generally seen to be warranted. While mental and physical health intervenes on the visible body, it is at the same time being operated on by culturally endorsed body management practices that prioritize, for example, beauty ideals and stable gender identities. These standardizing mechanisms (medicine and ideals of normality) function to limit possible identities that are not dressed with distress and personally and socially understood as such.

Transgenderist self-regulation of embodiment is understood to break down the pathology/normality divide and significantly challenge the link between distress and non-distress. In advocating choice, transgenderism not only becomes a site for the production of multiple, non-distressed subjectivities, but also for the positive construction and practice of body management options that are not perceived as pathological but as creative, good and pleasurable. As a consequence, it is suggested that community, health and social psychologists understand and attend to 'problematic' and (dis)ordered body management regimes as serving the regulatory and functional dictates of public health discourse and actions; prescriptions and actions that in themselves can necessitate and validate potentially self-damaging body management practices. Without the (public) health discourse as it is (and the wider social and political purposes it serves), perhaps the 'transsexual' would not only seek surgery or the 'anorexic' always opt for self-starvation.

The practical implications of this approach would be to look beyond individualized notions of 'poor body image' and 'low self-esteem' on which to base 'therapeutic' intervention. Conceiving it as a choice that may produce a particular pleasure and not just as a syndrome that is indicative of distress could support potentially selfdamaging practices, such as anorexia, more adequately. Where dangerous, the 'pleasure' of self-starvation (stemming perhaps, among other things, from a rejection of a particular female form and its culturally ascribed value) could be less dangerously expressed once the anorexic body manager is de-pathologized and allowed to perceive wider choices, such as not having to take up essentialized femininity.

In referring to the social function of the body, Marcus asserts that 'some people translate what they see in a very literal way. Some people have taught themselves to be able to see more than just the physical package. Those people are more likely to be able to appreciate the complexity of my situation'. It is by critically attending to more 
than just the 'physical package' and its label of distress that (dis)orders of embodiment and their complexity can be more adequately addressed. Indeed, the theoretical translation of such (dis)orders needs to be less literal (a 'wrong' body symbolizes a 'disordered' mind) and account made of the social, cultural and political origins and functions of such literalness. As a result, wider (social and health) choices to do with embodiment could be taken account of and validated in such a way that 'problematic' options are not always pathologized but seen as positively productive, and potentially damaging options not the only available ones to be consumed or taken up.

\section{ACKNOWLEDGEMENTS}

The authors wish to thank the reviewers for their helpful comments on an earlier draft.

\section{REFERENCES}

Billings, D. B. and Urban, T. (1996) 'The socio-medical construction of transsexualism: an interpretation and critique', in R. Ekins and D. King (eds), Blending Genders: Social Aspects of Cross-Dressing and Sex-Changing, Routledge, London.

Bolin, A. (1994) 'Transcending and transgressing', in G. Herdt (ed.), Third Sex, Third Gender: Beyond Sexual Dimorphism in Culture and History, Zone Books, New York.

Bordo, S. (1990) 'Reading the slender body', in M. Jacobus, E. Fox Keller and S. Shuttleworth (eds), Body/Politics: Women and the Discourses of Science, Routledge, London.

Bornstein, K. (1994) Gender Outlaw: On Men, Women and the Rest of Us, Vintage Books, New York.

Bordieu, P. (1984) Distinction: A Social Critique of the Judgement of Taste (trans. Richard Nice). Routledge, London.

Burman, E. and Parker, I. (1993) Discourse Analytic Research: Repertoires and Readings of Texts in Action, Routledge, London.

Butler, J. (1990) Gender Trouble: Feminism and the Subversion of Identity, Routledge, London.

Butler, J. (1998) 'Afterword', Sexualities, 1(3), 355-359.

Cooper, C. (1998) Fat and Proud: The Politics of Size, The Women's Press, London.

Crawford, R. (1985) 'A cultural account of health: self-control, release and the social body', in J. McKinlay (ed.), Issues in the Political Economy of Health Care, Methuen, New York.

Davies, K. (1995) Reshaping the Female Body: The Dilemma of Cosmetic Surgery, Routledge, London.

Davies, K. (1997) 'My body is my art', The European Journal of Women's Studies, 4, 23-37.

Davies, B. and Harré, R. (1990) 'Positioning theory: the discursive production of selves', Journal for the Theory of Social Behaviour, 20, 43-63.

Denny, D. (1996) 'In search of the true transsexual', Chrysalis: Journal of Transgressive Gender Identities, 2(3), 39-45.

Douglas, M. (1966) Purity and Danger, Routledge, Kegan Paul, London.

Douglas, M. (1982) Natural Symbols, Pantheon, New York.

Featherstone, M. (1991) 'The body in consumer culture', in M. Featherstone, M. Hepworth and B. S. Turner (eds), The Body: Social Processes and Cultural Theory, Sage, London.

Foucault, M. (1972) The Archaeology of Knowledge and the Discourse on Language (trans. A Sheridan). Pantheon Books, New York.

Foucault, M. (1977) Discipline and Punish: The Birth of the Prison (1987 edn). Penguin, London.

Copyright (C) 1999 John Wiley \& Sons, Ltd. J. Community Appl. Soc. Psychol. 9: 463-476 (1999) 
Foucault, M. (1979) The History of Sexuality, Vol. 1: An Introduction, Penguin, London.

Hall, S. (1982) 'The rediscovery of ideology: returning to the repressed in media studies', in M. Gurevitch, M. Bennett, J. Curan and J. Wollacott (eds), Culture, Society and the Media, Methuen, London.

Howard, R. (1993) 'Health costs of social degradation and female self-mutilation in North America', in K. E. Mahoney and P. Mahoney (eds), Human Rights in the Twenty-First Century: A Global Challenge, Martinus Nijhoff, Dordrecht, Netherlands.

Jeffreys, S. (1997) 'Transgender activism: a lesbian feminist perspective', Journal of Lesbian Studies, 1(3/4), 55-74.

Kulick, D. (1998) 'Fe/male trouble: the unsettling place of lesbians in the self-images of Brazilian 'Travesti' prostitutes', Sexualities, 1(3), 299-312.

Lancaster, R. (1998) 'Transgenderism in Latin America: some critical introductory remarks on identities and practices', Sexualities, 1(3), 261-274.

Lienert, T. (1998) 'Woman's self starvation, cosmetic surgery and transsexualism', Feminism and Psychology, 8(2), 245-250.

Malson, H. (1997) 'Anorexic bodies and the discursive production of feminine excess', in J. Ussher (ed.), Body Talk: The Material and Discursive Regulation of Sexuality, Madness and Reproduction, Methuen, London.

Malson, H. (1998) The Thin Woman: Feminism, Post-structuralism and the Social Psychology of Anorexia Nervosa, Routledge, London.

Malson, H. and Ussher, J. (1997) 'Beyond this mortal coil: femininity, death and discursive constructions of the anorexic body', Mortality, 2(1), 43-61.

Newton, T., Robinson, P. and Hartley, P. (1993) 'Treatment for eating disorders in the United Kingdom: Part II. Experiences of treatment: a survey of members of the Eating Disorders Association', Eating Disorders Review: The Journal of the Eating Disorders Association, 1(1), 10-22.

Parlee, M. (1998) 'Situated knowledges of personal embodiment: transgender activists' and psychological theorists' perspectives on 'sex' and 'gender", in H. Stam (ed.), The Body and Psychology, Sage, London.

Potter, J. and Wetherell, M. (1987) Discourse and Social Psychology: Beyond Attitudes and Behaviour, Sage, London.

Prosser, J. (1998) Second Skins: The Body Narratives of Transsexuality, Columbia University Press, New York.

Raymond, J. G. (1994) The Transsexual Empire: The Making of the She-Male, Teachers College Press, New York.

Riddell, C. (1996) 'Divided sisterhood: a critical review of Janice Raymond's the transsexual empire', in R. Ekins and D. King (eds), Blending Genders: Social Aspects of Cross-Dressing and Sex Changing, Routledge, London.

Rose, N. (1989) Governing the Soul: The Shaping of the Private Self, Routledge, London.

Ussher, J. (1997) 'Introduction: towards a material-discursive analysis of madness, sexuality and reproduction', in J. Ussher (ed.), Body Talk: The Material and Discursive Regulation of Sexuality, Madness and Reproduction, Routledge, London.

Whittle, S. (1996) 'Gender fucking or fucking gender?: Current cultural contributions to theories of gender blending', in R. Ekins and D. King (eds), Blending Genders: Social Aspects of Cross-Dressing and Sex-Changing, Routledge, London.

Wilson, K. (1997) Gender As Illness: Issues of Psychiatric Classification. http://www. transgender.org/tg/gic/icttext.html 